\title{
ORIGINAL
}

\section{Intensive care support and clinical outcomes of patients with Ebola virus disease (EVD) in West Africa}

\author{
Martin Langer ${ }^{1,2,3^{*}} \mathbb{D}$, Gina Portella ${ }^{3}$, Stefano Finazzi ${ }^{4}$, Liliane Chatenoud ${ }^{4}$, Simone Lanini ${ }^{5}$, Francesco Vairo ${ }^{5}$, \\ Robert Fowler ${ }^{6}$, Rossella Miccio ${ }^{3}$, Giuseppe Ippolito ${ }^{5}$, Guido Bertolini ${ }^{4}$ and Gino Strada ${ }^{3}$
}

(c) 2018 The Author(s)

\begin{abstract}
Purpose: We investigate the impact on outcome of different levels of supportive treatment in Ebola virus disease (EVD). The NGO EMERGENCY delivered care sequentially at two Ebola Treatment Centres (ETC) in Sierra Leone: first at Lakka (fluids, symptomatic, antibiotic, antimalaria treatment, and hospital level medical care), and thereafter in Goderich, adding organ support in the only African ETC with an equipped and staffed intensive care unit (ETC-ICU).

Methods: The primary outcome in this retrospective cohort study was in-ETC mortality. Secondarily, we used multivariable logistic regression to investigate the independent impact of the IC on mortality by comparing patients in two ETCs, adjusting for potential confounders, including the viral load (base-10 logarithm in copies $/ \mathrm{ml}$ ) (LVL), modelled as a piecewise linear function. Mortality was plotted versus LVL. Confidence bands were constructed by a bootstrap technique. The number of hospital-free days within 28 was computed to assess the burden of EVD.

Results: Data from 229 EVD patients were analysed (123 in Lakka, 106 in Goderich). Crude analysis showed a nonstatistically significant difference in mortality (57.7\% in Lakka vs 50.0\% in Goderich; $p=0.19$ ). Age and LVL were associated with mortality. Adjusted mortality was lower at the Goderich ICU-ETC $(p=0.055)$. This difference was observed with $80 \%$ confidence for patients with LVL between 7.5 and 8.5 copies/ml. Hospital-free days (of 28 days) were greater (7.7 vs 5.5; $p=0.03$ ) for patients treated in the ICU-ETC.
\end{abstract}

Conclusions: Provision of critical care to patients with EVD is feasible in resource-limited settings and was associated with improved survival and less time in hospital.

Keywords: Ebola virus disease, Intensive care, Multiple organ failure, Health-care in resource limited countries

\section{Introduction}

The Ebola virus disease (EVD) outbreak in West Africa in 2013-2016 was the largest, longest-lasting epidemic of its kind, and for the first time also involved non-African countries. The outbreak led to a broader understanding of Ebola epidemiology and heightened recognition of the need to respond rapidly to interrupt transmission early

${ }^{*}$ Correspondence: martin.langer@emergency.it

${ }^{3}$ EMERGENCY-NGO, Via Santa Croce 19, 20122 Milan, Italy

Full author information is available at the end of the article
[1]. Considerable progress has also been made on vaccine development [2-6], but there is still limited knowledge on EVD pathophysiology [7] and therapeutic yielded inconclusive findings [8-13].

Management guidelines [14] developed from previous outbreaks and available in 2013, focused on patient cohorting and healthcare worker safety, proposing treatments that could be delivered in resource-limited settings in rural areas with limited access to medical care.

In 2014, many groups operating in the field [15, 16] endorsed the need for more aggressive symptomatic treatment, treatment of dehydration and related 
electrolyte imbalances and organ-supporting care. Human resources and funding, combined with experience from EVD treatment of patients transported to North America and Europe, strengthened the idea of critical care provision in resource-constrained settings.

EMERGENCY, an Italian NGO (http://www.emerg ency.it), was founded in 1994 with the primary mission of delivering care to civilian war victims worldwide. Since 2001 it has also been running a Surgical and Paediatric Centre on the outskirts of Freetown, Sierra Leone. At the start of the epidemic, the Ministry of Health of Sierra Leone invited EMERGENCY to contribute to the fight against Ebola. The NGO rapidly built a patient assessment centre in Lakka to provide clinical triage, assessment and Ebola diagnostic testing, which soon became a patient Ebola Treatment Centre (ETC). A second ETC, in Goderich Sierra Leone was subsequently constructed, incorporating a well-equipped intensive care unit (ICU), capable of providing $24 \mathrm{~h}$ nursing and medical assessment/support, mechanical ventilation, intravenous vasoactive medications, and renal replacement therapy (Supplementary information, S2). To our knowledge, this was the first ever, dedicated ICU-ETC in Africa.

Our aims for this retrospective cohort study was to describe the feasibility of providing intensive care with organ-supporting treatment to patients with Ebola in a resource-limited setting, to describe patient outcomes, and to compare outcomes of patients between two distinct treatment settings (Goderich ETC with an ICU vs Lakka ETC with no ICU), adjusting for predictors of survival, including patient age and viral load at admission [17-23].

\section{Methods}

\section{Study design and setting}

This retrospective cohort study includes all consecutive patients affected by EVD hospitalized in two ETCs in Sierra Leone, from $19 / 09 / 2014$ to $12 / 12 / 2014$ in the Lakka Holding and Treatment Centre and from $12 / 12 / 2014$ to $28 / 05 / 2015$ in the Goderich ETC-ICU. Both ETCs were located near Freetown, Sierra Leone. More detailed information on the staff, facility, and operational procedures are provided in the Supplementary Material, S1 and S2. The main characteristics and differences are reported in Table 1.

\section{Laboratory}

The plasma concentration of Ebola virus (EBOV) RNA (viral load) was measured using a real-time reverse transcriptase PCR (RT-PCR) assay (RealStar Filovirus Screen. RT-PCR $1.0 \mathrm{kit}$, Altona Diagnostics), with a limit of detection of $10^{3} \mathrm{cp} / \mathrm{ml}$ of EBOV RNA. Viral RNA

\section{Take-home message:}

An Intensive Care Unit (ICU) as part of an Ebola Treatment Centre (ETC) was run by the NGO EMERGENCY and the Istituto Malattie Infettive "Spallanzani" in Goderich, Sierra Leone during the last 5 months in the 2013-16 outbreak. Building and running an ICU with western standard in an ETC was possible also in this very difficult setting. This allowed also some research activity, essential to evaluate the interventions directly on the field in real life conditions during an epidemic and with the pressure of large numbers of cases. The outcome of the 106 patients treated in the ICU-ETC was compared in a before-after study to the outcome of the previous cohort of 123 patients treated by the same NGO in Lakka without an ICU facility. Patient risk factors, mainly the viral load at admission were adjusted as potential confounders. The availability of the ICU in the ETC led to a lower mortality in Goderich $(p=0.055)$. This difference was observed with $80 \%$ confidence for patients with an intermediate range of viral load, indicating an intermediate probability of death (50-70\%). Relatively small numbers in each subgroup and other possible risk factors limit this analysis.

The already high level of care in Lakka, the first ETC, corresponding essentially to the recently published guidelines, can be improved with the availability of an Intensive Care Unit. However also the maximal supportive effort without effective antivirals seems not able to lower mortality to an acceptable level. Intensive care and effective antiviral seem both necessary in the fight against Ebola.

quantification was based on a standard reference curve provided by the kit manufacturer, spanning up to $10^{9} \mathrm{cp} /$ $\mathrm{ml}$ of EBOV RNA. For the sake of simplicity, further analyses were performed using the base 10 logarithm of the viral load (LVL) measured in $\mathrm{cp} / \mathrm{ml}$.

At the start of the epidemic, before implementing its own virology laboratory, EMERGENCY collaborated with the WHO South Africa Ebola laboratory, which used the same diagnostic test.

\section{Admitted patients}

Patients reaching the facility with suspected EVD were admitted, under observation, to the Holding and Treatment Centre, and their symptoms treated while awaiting the RT-PCR test results. Only patients with laboratoryconfirmed EVD from the holding centre, or those with EVD transferred from other facilities, were admitted for treatment.

\section{Risk factors at admission}

Demographic information including age, gender, symptoms, and possible time of Ebola exposure were collected on standardised clinical case report forms. LVL was recorded from the first diagnostic blood sample at admission. Other risk factors at admission, including markers of organ damage (renal, liver, coagulation etc.), were not systematically collected in the early months and cannot therefore be included in the analysis. 
Table 1 Main patient management characteristics of EMERGENCY NGO's two Ebola Treatment Centres (ETC) in Freetown, Sierra Leone; September 2014-May 2015

\begin{tabular}{|c|c|c|}
\hline & $\begin{array}{l}\text { ETC Lakka (September 19-December 13, } \\
\text { 2014) }\end{array}$ & $\begin{array}{l}\text { ETC-ICU Goderich (December 14, 2014-May } \\
28,2015 \text { ) }\end{array}$ \\
\hline Structure & Tents & Brick walls $(\mathrm{ICU})+$ tents \\
\hline Number of beds & 5 holding/17 treatment & 22 holding/24 ICU/50 ward \\
\hline Running water and electricity & Yes & Yes \\
\hline Air conditioning & Yes (inadequate) & Yes \\
\hline Oxygen & Yes (concentrators max $5 \mathrm{l} /$ person) & Yes (concentrators max $10 \mathrm{l} /$ person) \\
\hline Virology laboratory & External & Internal \\
\hline Laboratory at point-of-care & Partial/last weeks & Yes \\
\hline Radiology & No & Yes (from March 15/2015) \\
\hline $\begin{array}{l}\text { Standard monitoring (EKG, HR pulse oximetry, } \\
\text { non-invasive blood pressure) }\end{array}$ & Yes & Yes \\
\hline Urinary catheter and fluid balance & partially & Yes \\
\hline Artificial nutrition & Parenteral & Parenteral/enteral \\
\hline IV fluid replacement, where necessary & Yes & Yes \\
\hline Blood and blood products & Only whole O Rh neg blood & Yes \\
\hline Inotropes/vasoactive medication & Dopamine & Noradrenaline, Adrenaline, Dopamine \\
\hline Central venous lines & Yes, last month & Yes \\
\hline Arterial line and pressure monitoring & No & Yes \\
\hline Advanced cardiovascular monitoring (PICCO) & No & Yes \\
\hline Blood gas analyser & No & Yes \\
\hline Tracheal intubation and mechanical ventilation & No & Yes \\
\hline Continuous renal replacement therapy & No & Yes \\
\hline Individual time limit for working inside red zone & $60^{\prime}$ & $120^{\prime}$ \\
\hline No. doctors, mean & $5 \mathrm{MDs}$ & $14 \mathrm{MDs}$ \\
\hline No. international nurses, mean & 6 & 20 \\
\hline No. intensivisits, total & 2 intensivists & 5 intensivists \\
\hline Time in $\mathrm{h} / 24 \mathrm{~h}$ any $\mathrm{MD}$ present in red zone & 5 & 15 \\
\hline
\end{tabular}

The staff calculation was performed by calculating the mean number of staff members per month

\section{Definition of outcome}

A survivor is defined as a patient discharged alive. Discharge of patients from the ETCs occurred after two negative RT-PCR blood tests performed at least $24 \mathrm{~h}$ apart.

\section{Co-interventions: investigational antiviral treatments}

Fluids and electrolytes were administered by mouth or intravenously according symptoms, diuresis and fluid balance; all patients were treated for symptoms as nausea, anxiety, and pain. Antibiotics were administered from admission and antimalaria treatment was discontinued only if negative tests became available.

Only a few doses of compassionate use investigational antiviral treatments were available. Two patients received $\mathrm{ZMAb}$ and towards the end of the outbreak, Goderich ETC took part in the Prevail II trial [8], randomizing five patients to standard care plus ZMapp (two patients) versus standard care alone (three patients). Based on the available preclinical literature suggesting in vitro and in vivo efficacy [24], a randomised clinical trial protocol was developed to investigate the efficacy of treatment of EVD with amiodarone. The trial was registered at ClinicalTrials.gov (NCT02307591) (see Supplementary material S4 for details).

While awaiting clinical trial initiation, and after approval by two Italian Ethics Committees, given the pre-existing high mortality rate and lack of known effective therapies, amiodarone was administered on a compassionate basis to 100 patients. Compassionate use was stopped between December 2014 and February 2015 by request of the Sierra Leonean Government, pending the opinion of the specific Ethics Committee (definitive approval granted April 23, 2015). Further information on the treatment with amiodarone is reported in the Supplementary material S4.

\section{Statistical analysis}

Descriptive analyses were presented as frequencies, proportions, means and standard deviations, medians and interquartile ranges (IQR), where appropriate to 
characterize patients and their clinical outcomes. Proportions were compared using the $\chi^{2}$ test or Fisher Test, whereas comparisons between continuous variables were expressed through the $t$ test or Wilcoxon rank-sum test, as appropriate. The number of hospital-free days within 28 days was calculated to compare the burden of EVD in terms of hospitalization in the two ETCs, avoiding bias due to mortality rate differences [25]. During the 28-day follow-up period most, but not all, EVD patients either died or recovered. The number of hospital-free days for a patient with $x$ days of hospitalisation was $28-x$, if the patient recovered within 28 days, and 0 if the patient recovered after 28 days or died. Hence, the higher the value of this indicator the lower the burden of hospitalization (as the patient recovered earlier), while deceased patients were considered equivalent to alive patients with a long recovery time.

Multivariable logistic regression models were used to determine independent factors associated with EVD patient mortality. ETC was forced in the model to explore the secondary endpoint of association of intensive care availability on mortality. To test any relationship between the logit and the LVL, the former was modelled as a continuous piecewise linear function of the latter. The Akaike Information Criterion (AIC) [26] was minimised with respect to the cut-off values of LVL where the slope of the piecewise linear function changed. Interactions between ETC and the other variables were only included when they significantly reduced the AIC. The interaction between ETC and the above-described transformation of the viral load was also tested in this step. This allowed different piecewise linear transformations (parametrised by the number and values of the cut-offs) of the LVL for the two ETCs. Missing records were excluded from the analysis.

The odds ratio (OR) of the two ETCs, i.e., the exponential of the difference $d$ between the logit of the two ETCs $\left(d=\operatorname{logit}_{\text {Lakka }}-\operatorname{logit}_{\text {Goderich }}\right)$, was plotted as a function of viral load, with the bootstrap-based confidence band. Hence, mortality in Lakka was higher than in Goderich when OR was larger than one. The OR was statistically significant for those viral load values for which the confidence band was above the line $\mathrm{OR}=1$. To identify the range of clinically relevant phenomena, two confidence bands were constructed at the 95 and 80\% levels, respectively.

The adjusted probability of death was then plotted for each ETC with the respective confidence bands to determine how mortality varied as a function of viral load in the two ETCs. All variables except LVL and ETC were chosen to be equal to their mean values. The width of the confidence bands for Lakka and Goderich was estimated by Payton et al. [27] approximate method. This procedure is designed to evaluate, with a given significance level, whether two confidence intervals overlap (Supporting information, S5).

The role played by viral load at admission as a predictor of mortality within 20 days of hospitalisation, was also described using Kaplan-Meier curves in strata of LVL, overall and for each ETC (Fig. 2). The cut-offs separating the strata were determined as the LVL values at which mortality in one ETC becomes higher or lower than in the other ETC at the $80 \%$ confidence level (as described in the previous paragraph). Graphically, these values correspond to the points where the $80 \%$ confidence band of the logit difference $d$ crosses the horizontal axis $d=0$. Differences between Kaplan-Meier curves in these strata were assessed by the log-rank test.

$p$ values lower than 0.05 were considered significant in two-tailed tests. All analyses were performed using $\mathrm{R}$ software, version 3.3.3, and SAS software, version 9.4.

More details on the statistical elaboration are reported in Supplementary materials, S5.

\section{Funding}

Goderich ETC was built during the outbreak, in the framework of a project to build seven Ebola treatment centres funded by DFID (Department for International Development-GOV.UK). In accordance with treatment criteria and based on the previous 3 months' experience, the Centre was co-designed by EMERGENCY's technical/engineering staff. Fitting it out for intensive care delivery resulted in additional costs, borne by the NGO, in the amount of approximately $€ 450,000$. The Istituto di Malattie Infettive "Lazzaro Spallanzani", which ran the virological laboratory, was supported by a "Ricerca Corrente IRCCS" grant; Ministry of Foreign Affairs, Italy (See Supplementary material S2 for more details). The funders had no role in study design, data collection and analysis, decision to publish, or preparation of the manuscript.

\section{Results \\ Patients and settings}

Data were analysed on 229 patients with a laboratoryconfirmed diagnosis of EVD, admitted to the two ETCs (123 at the ETC in Lakka, 106 at the ETC-ICU in Goderich). All patients with confirmed EVD received supportive treatment and were followed up to the endpoint (recovery or death). The study flow chart is shown in the supplementary material (Fig S3.1).

The patients admitted to the ETCs did not differ in terms of gender, while patients admitted to GoderichETC were older (mean age 29.7) than those admitted to Lakka-ETC (mean age 27.8 years) $(p=0.02$ ). 
Table 2 Demographic and clinical characteristics of 227 Ebola virus disease (EVD) patients at admission to two Ebola treatment centres (ETC)

\begin{tabular}{|c|c|c|c|c|}
\hline & $\begin{array}{l}\text { Total }(N=229) \\
N(\%)\end{array}$ & $\begin{array}{l}\text { Lakka-ETC }(N=123) \\
N(\%)\end{array}$ & $\begin{array}{l}\text { Goderich-ETC }(N=106) \\
N(\%)\end{array}$ & $p$ value ${ }^{a}$ \\
\hline \multicolumn{5}{|l|}{ Sex } \\
\hline Women & $114(49.8)$ & $60(48.8)$ & $54(51.0)$ & 0.74 \\
\hline Age, years (mean/median/(IQR) & $29.7,27.0 /(20.0-38.0)$ & $27.8,26.0 /(20.0-36.0)$ & $31.8,29.0 /(20.0-42.0)$ & 0.02 \\
\hline $0-10$ & $22(9.6)$ & $15(12.2)$ & $7(6.7)$ & \\
\hline $11-18$ & $28(12.2)$ & $12(9.8)$ & $16(15.4)$ & \\
\hline $19-45$ & $145(63.3)$ & $85(69.1)$ & $60(57.7)$ & \\
\hline$\geq 46$ & $32(14.0)$ & $11(8.9)$ & $21(20.2)$ & \\
\hline Missing & $2(0.9)$ & - & $2(1.9)$ & \\
\hline \multicolumn{5}{|l|}{ LVL (copies/ml) at admission } \\
\hline$<7.5$ & $84(36.7)$ & 49 (39.8) & $35(33.0)$ & \\
\hline $7.5-8.4$ & $78(34.1)$ & $42(34.1)$ & $36(34.0)$ & 0.29 \\
\hline$\geq 8.5$ & $47(20.5)$ & $21(17.1)$ & $26(24.5)$ & \\
\hline Missing & $20(8.7)$ & $11(8.9)$ & $9(8.5)$ & \\
\hline Mean/median/(IQR) & $7.6 / 7.8 /(6.9-8.5)$ & $7.6 / 7.8 /(6.8-8.4)$ & 7.7/7.9/(7.1-8.6) & \\
\hline $\begin{array}{l}\text { Time between symptom onset and hospital admission (day), } \\
\text { mean/median/(IQR) }\end{array}$ & $4.9 / 4.0 /(3.0-6.0)$ & $5.0 / 4.0 /(3.0-6.0)$ & $4.8 / 5.0 /(3.0-6.0)$ & 0.95 \\
\hline $0-2$ & $43(18.8)$ & $24(19.5)$ & $19(17.9)$ & \\
\hline $3-5$ & $101(44.1)$ & $55(44.7)$ & $46(43.4)$ & \\
\hline$>5$ & $76(33.2)$ & $44(35.8)$ & $32(30.2)$ & \\
\hline Missing & $9(3.9)$ & - & $9(8.5)$ & \\
\hline
\end{tabular}

LVL base-10 logarithm of viral load, measured in copies per $\mathrm{ml}$

IQR Interquartile range

${ }^{a} x^{2}$ test or Fisher's exact test or Wilcoxon's Rank-Sum Test for continuous variables

Table 3 Hospital stay and hospital-free days in two Ebola Treatment Centres (ETC)

\begin{tabular}{|c|c|c|c|c|}
\hline & $\begin{array}{l}\text { Total }(N=229) \\
N(\%)\end{array}$ & $\begin{array}{l}\text { Lakka-ETC }(N=123) \\
N(\%)\end{array}$ & $\begin{array}{l}\text { Goderich-ETC }(N=106) \\
N(\%)\end{array}$ & $p$ value $^{a}$ \\
\hline Hospital stay (days), mean, medan/(IQR) & $9.2,8.0 /(4.0-14.0)$ & $9.3,8.0 /(4.0-14.0)$ & $9.0,8.0 /(4.0-13.0)$ & 0.66 \\
\hline $0-4$ & $73(32.2)$ & $39(31.7)$ & $34(32.7)$ & \\
\hline $5-10$ & $60(26.4)$ & $30(24.4)$ & $30(28.8)$ & \\
\hline$\geq 11$ & $94(41.4)$ & $54(43.9)$ & $40(38.5)$ & \\
\hline $\begin{array}{l}\text { Hospital-free days within } 28 \text { days of hospitalisation, mean/median/ } \\
\text { (IQR) }\end{array}$ & $6.5,0.0(0.0-14.0)$ & $5.5,0.0(0.0-13.0)$ & $7.7,2.5(0.0-15.0)$ & 0.03 \\
\hline $0^{b}$ & $126(55.0)$ & $73(59.3)$ & $53(50.0)$ & \\
\hline $1-14$ & $52(22.7)$ & $31(25.2)$ & $21(19.8)$ & \\
\hline $15-28$ & $50(21.8)$ & $19(15.5)$ & $31(29.2)$ & \\
\hline
\end{tabular}

IQR Interquartile range

${ }^{\text {a }} x^{2}$ test or Fisher exact test

b This category includes 71 and 53 patients who died in Lakka and Goderich, respectively, plus two survivors from Lakka and one from Goderich, discharged after 28 days

No major differences emerged between ETCs for admission viral load, or time from symptom onset to ETC-admission (Table 2).

The clinical manifestations and contact history of the 229 EVD patients are shown in the Supplementary material S3. None of the 13 clinical symptoms reported during the admission visit were significantly associated with mortality. The provision of interventions associated with intensive care were more common at the Goderich ETC-ICU: central venous catheter in 62 versus 12 
Table 4 Case fatality rate by main patient characteristics

\begin{tabular}{|c|c|c|c|c|}
\hline & Survivors & Non-survivors & Case fatality rate $(\%)$ & $p$ value $^{\mathrm{a}}$ \\
\hline All patients, $N$ & 105 & 124 & 54.1 & \\
\hline \multicolumn{5}{|l|}{ ETC } \\
\hline Lakka & 52 & 71 & 57.7 & 0.19 \\
\hline Goderich & 53 & 53 & 50.0 & \\
\hline \multicolumn{5}{|l|}{$\operatorname{Sex}, N(\%)$} \\
\hline Women & 56 & 58 & 50.9 & 0.32 \\
\hline Men & 49 & 66 & 57.4 & \\
\hline Age (years), mean, median (IQR) & $29.7 / 27.0 /(20.0-38.0)$ & 29.9/27.5/(20.0-37.0) & & 0.73 \\
\hline $0-10$ & 8 & 14 & 63.6 & 0.74 \\
\hline $11-18$ & 12 & 16 & 57.1 & \\
\hline $19-45$ & 70 & 75 & 51.7 & \\
\hline$\geq 46$ & 15 & 17 & 53.1 & \\
\hline Missing & - & 2 & - & \\
\hline LVL at admission, mean, median (IQR) & $7.1 / 7.1 /(6.4-7.9)$ & $8.1 / 8.2 /(7.7-8.8)$ & & $<0.0001$ \\
\hline$<7.5$ & 58 & 26 & 31.0 & $<0.0001$ \\
\hline $7.5-8.4$ & 32 & 46 & 59.0 & \\
\hline$\geq 8.5$ & 5 & 42 & 89.4 & \\
\hline Missing & 10 & 10 & - & \\
\hline $\begin{array}{l}\text { Time between symptom onset and hospital admission (days), mean, } \\
\text { median (IQR) }\end{array}$ & $5.1,5.0(3.0-6.0)$ & $4.8,4.0(3.0-7.0)$ & $4.8,5.0(3.0-6.0)$ & 0.39 \\
\hline $0-2$ & 17 & 26 & 60.5 & 0.42 \\
\hline $3-5$ & 50 & 51 & 50.5 & \\
\hline$>5$ & 33 & 43 & 56.6 & \\
\hline Missing & 5 & 4 & - & \\
\hline
\end{tabular}

$L V L$, base-10 logarithm of the viral load, measured in copies per millilitre

$I Q R$ Interquartile range

${ }^{a} X^{2}$ test or Fisher's exact test, or Wilcoxon's Rank-Sum Test for continuous variables

patients (58.5 vs 9.8\%, $p<0.0001$ ), mechanical ventilation for any duration in $33(14.4 \%)$ and renal replacement therapy in $21(9.2 \%)$ versus no patients in the ETC Lakka. Twenty patients had both ventilation and renal replacement therapy. Dopamine infusion was the only vasoactive medication possible in Lakka (12 patients; 1 survivor); Noradrenaline and/or Adrenaline (26 patients; 3 survivors), administered via syringe-pump and invasive monitoring of arterial pressure, central venous pressure and advanced hemodynamic assessment (Picco) in selected patients, were available in Goderich.

\section{Clinical outcomes}

The mean number of hospital-free days (of 28) days of admission was significantly higher in the Goderich ETCICU (7.7 vs 5.5 days; $p=0.03$, Table 3$)$.

The overall crude case fatality rate (CFR) was $54.1 \%$ (Table 4). No statistical differences were observed between patients who survived and who died of EVD in terms of gender, age and time from symptom onset to hospital admission. CFR differed substantially according viral load at admission, ranging from approximately $30 \%$ for patients with $L V L<7.5$ (low) to over $80 \%$ for patients with $L V L \geq 8.5$ (high) $(p<0.0001)$. Crude analysis showed a non-statistically significant difference in CFR between Lakka-ETC and Goderich-ETC-ICU patient admissions (57.7 vs $50.0 \% ; p=0.19$ ) (Table 4 ). Multivariable logistic regression analysis showed that age and viral load were independently associated with an increase in EVD mortality. The best model (according to the lowest AIC) for predicting the probability of death included age, LVL, ETC, and the interaction between LVL and ETC. As known, an interaction involving a continuous variable (like LVL) is difficult to represent. Hence, in Fig. 1 we plotted, as a function of LVL, both the OR for mortality of Lakka vs Goderich (left panel) and the probability of death at each ETC (right panel). In the left panel, the 95\% confidence band of the OR (light grey) never exceeds one, while the $80 \%$ confidence band (dark grey) exceeds one for medium-high viral loads (LVL between 7.5 and 8.5).

Notably, as the confidence level varies, the band begins to exceed zero at a confidence level of $94.5 \%$, corresponding to $p=0.055$. This means that patients with a medium-high level of viremia at admission, had a 

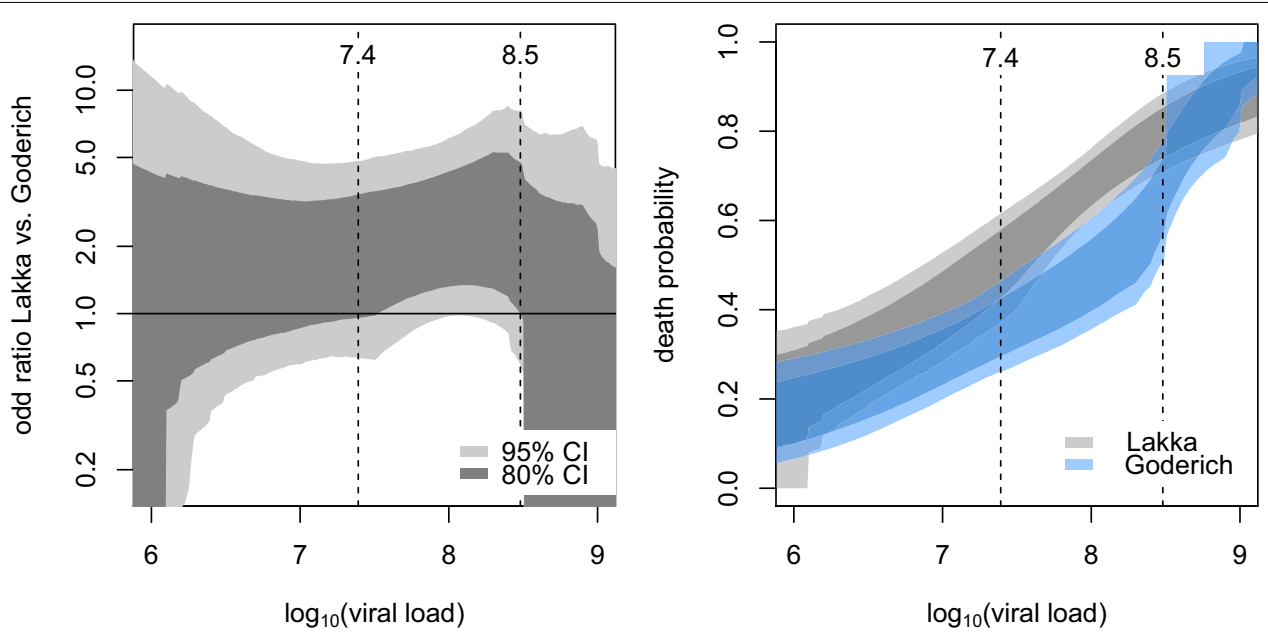

Fig. 1 Left panel: 95\% (light gray) and 80\% (dark gray) confidence bands of the OR of Lakka ETC vs Goderich ETC by LVL at admission. Right panel: confidence bands of probability of death by LVL at admission, stratified by ETC: The two 80\% confidence bands of the probability of death (dark grey for ETC Lakka, dark blue for ETC-ICU Goderich) do not overlap at LVL values between 7.4 and 8.5, whereas the two $95 \%$ confidence bands (light grey, light blue) are not separate. The plot shows that mortality at Lakka steadily increased with the rise in viral load, even for low-medium LVL levels. Conversely, in the medium viral load range, i.e. for LVL up to around 8.3, mortality at Goderich increased less substantially with the increase in LVL. Mortality at the two ETCs was similar at higher viral loads

statistically significant survival benefit (with $80 \%$ confidence level) if admitted to the treatment facility in Goderich with ICU competences and equipment.

Figure 2 shows the importance of the viral load at admission for the outcome of the overall population as Kaplan-Meier survival-curve for patients with low, intermediate and high viral loads at admission (panel a). The same analysis split in patient population of Lakka (panel b) and Goderich (panel c) shows how the intermediate line, corresponding to patients with LVL 7.5-8.5, is different in the two settings.

\section{Discussion}

Building an ICU in Sierra Leone dedicated to patients with EVD was founded on the hypothesis that intensive supportive care could improve the prognosis of EVD, and ethically supported by the conviction of the right of everybody to receive the best possible treatment. Based on this framework, the EMERGENCY NGO sought to optimise supportive care in a country where very few hospitals even had an ICU prior to the start of the epidemic.

After the tend-based ETC in Lakka, the Goderich ETCICU has been active since December 2014. It was built by the British government and run by EMERGENCY (Supplementary material, S2). The organisation recruited intensivists, infectious disease specialists, and expert nurses from various nations (Supplementary material, S1), coordinating their expertise with the experience of its own staff, specialised in intensive care medicine. Despite a long track record in hospital management in very difficult, dangerous areas and conditions, setting up a multinational ICU compliant with rigorous biosafety requirements and subject to obvious communication barriers among team members and with patients, proved to be a very challenging experience, highlighting the importance of organization, communication and crossdisciplinary and cross-cultural training.

We found that the setup of an ETC-ICU was feasible in a very short time and at relatively limited costs. Intensive supportive treatment shows shorter time to discharge in survivors (Table 3) and survival advantage in patients with intermediate-severe infection (Table 4, Fig. 1). Different factors, like delay in admission, organ failure, comorbidities, complications, factors not changed by the availability of intensive care, contribute to the mortality in patients with "low" Ebola viral load $(\mathrm{LVL}<7.5)$. Patients with very high viral load ( $L V L>8.5)$ may have a very limited benefit from intensive care support without effective antiviral treatment, because of the rapid progression of EVD to fatal multiple organ failure [28]. Only exceptionally it was possible to buy enough time for the immune system to clear the virus and reverse organ failure. Only $10 \%$ of the patients who needed mechanical ventilation, continuous renal replacement therapy and vasopressors recovered. In the supplementary material S6 we report two case histories, demonstrating how rapid both, worsening and improving, may occur according the clearance/persistence of the viral load.

Despite supportive treatment very close to the new guidelines [29] plus IC support, mortality at the 

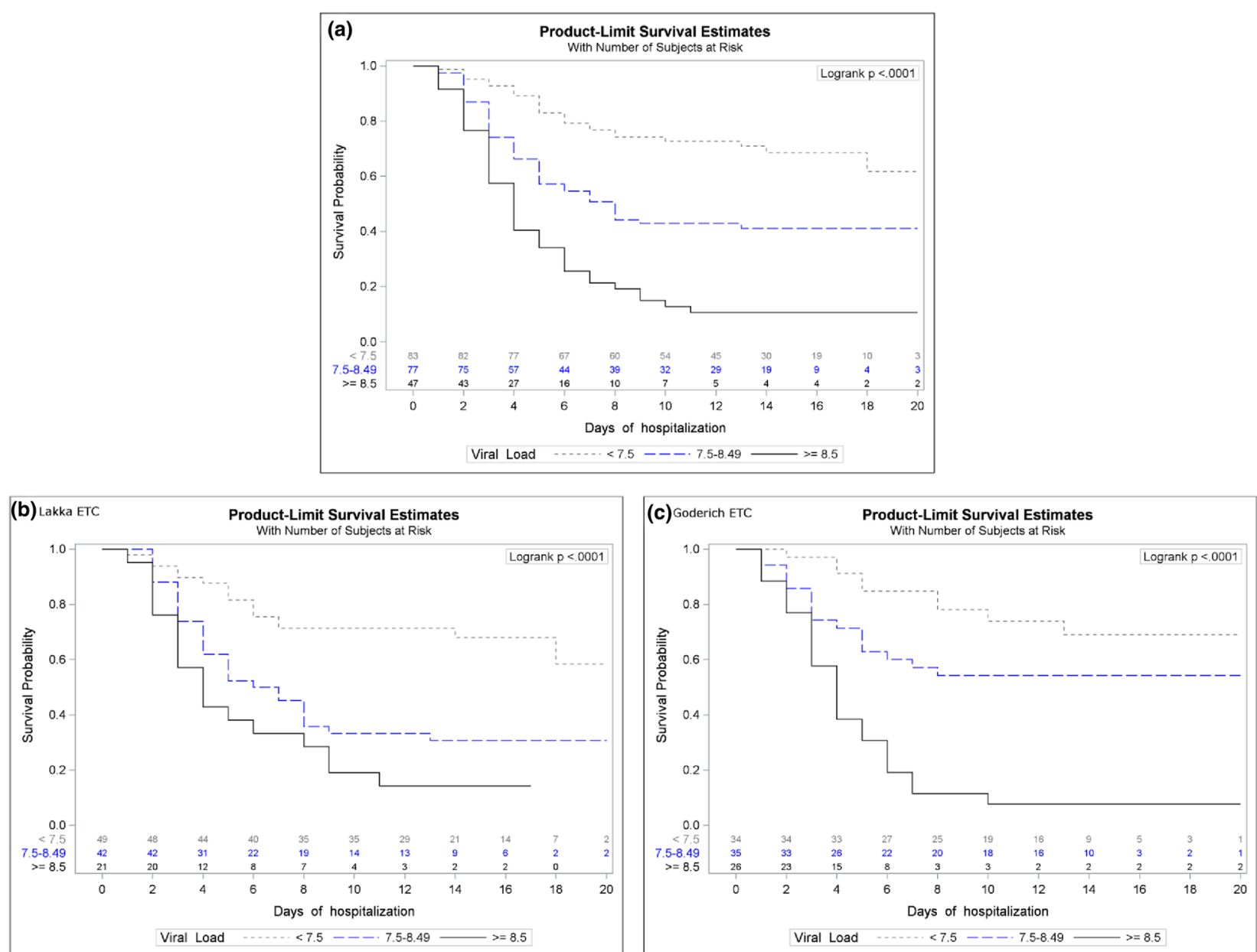

Fig. 2 Kaplan-Meier survival-curve for patients with low, intermediate and high viral loads at admission (a) and for Lakka (b) and Goderich (c), separately

ICU-ETC was $50 \%$ overall and still $30 \%$ in patients with LVL $<7.5$ (Table 4, Fig. 2). Our fatality rate is therefore much higher than the rate of $18.5 \%$ reported for patients with EVD treated outside of West Africa [30]. While it is not possible to make a direct comparison between those two groups of patients and their treatment, there remains undoubtedly an important gap which needs to be investigated. Relevant differences between the two patient populations and the treatments are: $81 \%$ of patients treated outside West Africa were Western healthcare workers (vs $1 \%$ in our population) with shorter time from symptom onset to diagnosis (3 vs 4 days), lower viral load at admission (mean values of LVL of 7.3 vs $7.8 \mathrm{copies} / \mathrm{ml}$ ), and earlier treatment onset (4 vs 4.9 days). Moreover, $85 \%$ of patients treated in North America and Europe received at least one antiviral drug, and $70 \%$ received two or more such treatments. Although the various clinical trials have not demonstrated the efficacy of the investigational treatments, some have exhibited promising findings that could not be adequately investigated $[8,11]$.

\section{Limitations of the study}

Evaluating the efficacy of an intensive care approach, with a limited number of patients, in the framework of a humanitarian intervention during a major epidemic, in one of the world's most recourse-limited regions, is clearly fraught with limitations. Outcome predictors other than age and viral load as pre-existing chronical illness and severity of organ dysfunction could not be included because of lack of complete information.

It is important to recognize that the cause of death, particularly when occurring 10-15 days after admission, may not be related solely to EVD but may also be associated with cardiovascular complications or bacterial superinfections. Finally, there is no way of assessing how far a learning curve in the treatment of EVD patients may have influenced outcomes, irrespective of the therapeutic 
setting. An important mortality reduction is reported in an earlier experience [31] but the lack of risk adjustment in the comparison limits the strength of this observation.

\section{Conclusions}

Provision of intensive care to patients within an EVD epidemic is feasible also in resource-limited settings and may be associated with improved survival and less time in hospital but the outcome with supportive care alone, without effective antiviral treatment, remains unsatisfactory.

\section{Electronic supplementary material}

The online version of this article (https://doi.org/10.1007/s00134-018-5308-4) contains supplementary material, which is available to authorized users.

\section{Author details \\ ${ }^{1}$ Dipartimento di Oncologia e Onco-Ematologia, University of Milan, Milan, Italy. ${ }^{2}$ IRCCS Istituto Nazionale dei Tumori, Milan, Italy. ${ }^{3}$ EMERGENCY-NGO, Via Santa Croce 19, 20122 Milan, Italy. ${ }^{4}$ Dipartimento di Epidemiologia Clinica, IRCCS Istituto di Ricerche Farmacologiche "Mario Negri", Ranica, BG, Italy. ${ }^{5}$ IRCCS Istituto Nazionale Malattie Infettive "Lazzaro Spallanzani", Rome, Italy. ${ }^{6}$ Departments of Medicine and Critical Care Medicine, Sunnybrook Hospital, Toronto, ON, Canada.}

\section{Acknowledgments \\ Goderich ETC was built by the Royal Engineers as a proxy for the Depart- ment for International Development, UK Government (DFID), in cooperation with EMERGENCY's Technical Division. The ETC's operations were cofounded by DFID and private donations to EMERGENCY. The virology laboratory was upgraded with the support of a grant from the Italian Ministry of Foreign Affairs-Direzione General per la Cooperazione allo Sviluppo (DGCS). INMI's research activities were performed thanks to grants from the Italian Ministry of Health (Ricerca Corrente IRCCS and Ricerca Finalizzata). Deployment of labora- tory personnel was made possible by a grant from the Italian Ministry of For- eign Affairs-DGCS. We thank the EMLab European consortium (IFS/2011/272- 372; http://www.emlab.eu), where we developed knowledge and experience allowing us to establish the virology laboratory at Goderich ETC, and the WHO South Africa Ebola laboratory for performing tests in the early phase of the epidemics. SF was supported by Fondazione Cariplo through Grant [2014-1962]. The authors thank Joanne Fleming for her help with the English editing of the text and Alessandro Soave for his help with figures editing.}

\section{Compliance with ethical standards}

\section{Conflict of interest}

The authors declare that no competing interests exist.

\section{Open Access}

This article is distributed under the terms of the Creative Commons Attribution-NonCommercial 4.0 International License (http://creativecommons.org/ licenses/by-nc/4.0/), which permits any noncommercial use, distribution, and reproduction in any medium, provided you give appropriate credit to the original author(s) and the source, provide a link to the Creative Commons license, and indicate if changes were made.

Received: 12 June 2018 Accepted: 6 July 2018

Published online: 30 July 2018

\section{References}

1. Ebola Response Team WHO, Agua-Agum J, Allegranzi B, Ariyarajah A, Aylward R, Blake IM, Barboza P et al (2016) After Ebola in West Africaunpredictable risks, preventable epidemics. N Engl J Med 375:587-596
2. Henao-Restrepo AM, Camacho A, Longini IM, Watson CH, Edmunds WJ, Egger $\mathrm{M}$ et al (2017) Efficacy and effectiveness of an rVSV-vectored vaccine in preventing Ebola virus disease: final results from the Guinea ring vaccination, open-label, cluster-randomised trial. Lancet 389:505-518

3. Zhu FC, Wurie AH, Hou LH, Liang Q, Li YH, Russell JB et al (2017) Safety and immunogenicity of a recombinant adenovirus type- 5 vector-based Ebola vaccine in healthy adults in Sierra Leone: a single-centre, randomised, double-blind, placebo-controlled, phase 2 trial. Lancet 389:621-628

4. Regules JA, Beigel JH, Paolino KM, Voell J, Castellano AR, Hu Z et al (2017) A recombinant vesicular stomatitis virus Ebola vaccine. N Engl J Med 376:330-341

5. Gsell PS, Camacho A, Kucharski AJ, Watson CH, Bagayoko A, Nadlaou SD et al (2017) Ring vaccination with rVSV-ZEBOV under expanded access in response to an outbreak of Ebola virus disease in Guinea, 2016: an operational and vaccine safety report. Lancet Infect Dis. https://doi. org/10.1016/s1473-3099(17)30541-8 (Epub ahead of print)

6. Schieffelin JS (2017) An effective and safe vaccine will not be enough to prepare us for the next Ebola outbreak. Lancet Infect Dis. https://doi. org/10.1016/s1473-3099(17)30575-3 (Epub ahead of print)

7. Baseler L, Chertow DS, Johnson KM, Feldmann H, Morens DM (2017) The pathogenesis of Ebola virus disease. Annu Rev Pathol 12:387-418

8. PREVAIL II Writing Group, Multi-National PREVAIL II Study Team, Davey RT Jr, Dodd L, Proschan MA, Neaton J, Neuhaus Nordwall J, Koopmeiners JS et al (2016) A randomized, controlled trial of ZMapp for Ebola virus infection. N Engl J Med 375:1448-1456

9. Dunning J, Kennedy SB, Antierens A, Whitehead J, Ciglenecki I, Carson G et al (2016) Experimental treatment of Ebola virus disease with brincidofovir. PLoS One 11:e0162199. https://doi.org/10.1371/journal.pone.0162199

10. Dunning J, Sahr F, Rojek A, Gannon F, Carson G, Idriss B, Experimental Treatment of Ebola Virus Disease with TKM-130803 et al (2016) A single-arm Phase 2 clinical trial. PLoS Med 13(4):e1001997. https://doi. org/10.1371/journal.pmed.1001997 (eCollection2016)

11. Sissoko D, Laouenan C, Folkesson E, M'Lebing AB, Beavogui AH, Baize $S$ et al (2016) Experimental Treatment with Favipiravir for Ebola virus disease (the JIKI trial): a historically controlled, single-arm proof-of-concept trial in Guinea. PLoS Med 13:e1001967. https://doi.org/10.1371/journ al.pmed.1001967

12. Gignoux E, Azman AS, de Smet M, Azuma P, Massaquoi M, Job D et al (2016) Effect of artesunate-amodiaquine on mortality related to Ebola virus disease. New Engl J Med 374:23-32

13. van Griensven J, Edwards T, de Lamballerie X, Semple MG, Gallian P, Baize $S$ et al (2016) Evaluation of convalescent plasma for Ebola virus disease in Guinea. N Engl J Med 374:33-42

14. Medicines Sans Frontières, Sterk E, Borchert M, Coeur C, Dorion C, Fabiansen C, Flevaud L et al (2008) Filovirus haemorrhagic fever guideline 2008, chapter 5: patient care. https://www.medbox.org/ebola-guidelines /listing. Accessed July 2017

15. Fowler RA, Fletcher T, Fischer WA, Lamontagne F, Jacob S, Brett-Major D et al (2014) Caring for critically ill patients with Ebola virus disease. Perspectives from West Africa. Am J Respir Crit Care Med 19:733-737

16. Perner A, Fowler RA, Bellomo R, Roberts I (2015) Ebola care and research protocols. Intensive Care Med 41:111-114

17. Faye $\mathrm{O}$, Andronico A, Faye $\mathrm{O}$, Salje H, Boëlle PY, Magassouba N et al (2015) Use of viremia to evaluate the baseline case fatality ratio of Ebola virus disease and inform treatment studies: a retrospective cohort study. PLoS Med 12:e1001908. https://doi.org/10.1371/journal.pmed.1001908 (eCollection 2015 Dec)

18. Schieffelin JS, Shaffer JG, Goba A, Gbakie M, Gire SK, Colubri A et al (2014) Clinical illness and outcomes in patients with Ebola in Sierra Leone. N Engl J Med 371:2092-2100

19. Lanini S, Portella G, Vairo F, Kobinger GP, Pesenti A, Langer M et al (2015) Blood kinetics of Ebola virus in survivors and non-survivors. J Clin Invest 125:4692-4698

20. de La Vega MA, Caleo G, Audet J, Qiu X, Kozak RA, Brooks Jl et al (2015) Ebola viral load at diagnosis associates with patient outcome and outbreak evolution. J Clin Invest 125:4421-4428

21. Fitzpatrick G, Vogt F, Moi Gbabai OB, Decroo T, Keane M, De Clerck H et al (2015) The contribution of Ebola viral load at admission and other patient characteristics to mortality in a Médecins Sans Frontières Ebola Case Management Centre, Kailahun, Sierra Leone, June-October 2014. J Infect Dis 212:1752-1758 
22. Hunt L, Gupta-Wright A, Simms V, Tamba F, Knott V, Tamba K et al (2015) Clinical presentation, biochemical, and haematological parameters and their association with outcome in patients with Ebola virus disease: an observational cohort study. Lancet Infect Dis 15:1292-1299

23. Crowe SJ, Maenner MJ, Kuah S, Erickson BR, Coffee M, Knust B et al (2016) Prognostic indicators for Ebola patient survival. Emerg Infect Dis 22:217-223

24. Salata C, Baritussio A, Munegato D, Calistri A, Ha HR, Bigler L et al (2015) Amiodarone and metabolite MDEA inhibit Ebola virus infection by interfering with the viral entry process. Pathog Dis. https://doi.org/10.1093/ femspd/ftv032

25. Schoenfeld DA, Bernard GR (2002) Statistical evaluation of ventilatorfree days as an efficacy measure in clinical trials of treatments for acute respiratory distress syndrome. Crit Care Med 30:1772-1777

26. Akaike H (1974) A new look at the statistical model identification. IRRR Trans Autom Control 19:716-723
27. Payton ME, Greenstone MH, Schenker N (2003) Overlapping confidence intervals or standard error intervals: what do they mean in terms of statistical significance? J Insect Sci 34:1-6

28. Lanini S, Portella G, Vairo F, Kobinger GP, Pesenti A, Langer M et al (2017) Relationship between viremia and specific organ damage in Ebola patients: a cohort study. Clin Infect Dis 66:36-44

29. Lamontagne F, Fowler RA, Adhikari NK, Murthy S, Brett-Major DM, Jacobs $M$ et al (2018) Evidence-based guidelines for supportive care of patients with Ebola virus disease. Lancet 39:700-708

30. Uyeki TM, Mehta AK, Davey RT Jr, Liddell AM, WolfT, Vetter P et al (2016) Clinical management of Ebola virus disease in the United States and Europe. N Engl J Med 374:636-646

31. Ansumana $R$, Jacobsen $\mathrm{KH}$, Sahr F, Idris M, Bangura $H$, Boie-Jalloh $M$, Lamin JM, Sesay S (2015) Ebola in Freetown area, Sierra Leone-a case study of 581 patients. N Engl J Med 372:587-588 